\title{
Is Malaysia Ready for Sustainable Energy? Exploring the Attitudes toward Solar Energy and Energy Behaviors in Malaysia
}

\author{
Ai Ni Teoh ${ }^{1, *(1)}$, Yun Ii Go ${ }^{2}$ (i) and Tze Chuen Yap ${ }^{2}$ (I) \\ 1 School of Social and Health Sciences, James Cook University, Singapore 387380, Singapore \\ 2 School of Engineering and Physical Sciences, Heriot-Watt University Malaysia, Putrajaya 62200, Malaysia; \\ y.go@hw.ac.uk (Y.I.G.); t.yap@hw.ac.uk (T.C.Y.) \\ * Correspondence: aini.teoh@jcu.edu.au
}

Received: 30 June 2020; Accepted: 27 July 2020; Published: 1 August 2020

check for updates

\begin{abstract}
To meet the larger demand for electricity supply, Malaysia needs to achieve two main psychosocial conditions, among others-having the awareness of renewable energy and demonstrating energy-conserving behavior. To examine whether Malaysia has met these two conditions, we recruited 225 participants ( $n=109$ women, $n=113$ men, $n=3$ did not indicate) to complete a series of questionnaires. The results showed that the public was aware of the option of solar energy but was not ready to install solar photovoltaic panels after being told the cost incurred. Furthermore, the public did not show satisfying energy-conserving behaviors. To boost the installation of solar power, increasing the public's energy knowledge and implementing policies to reduce the installation cost might be helpful. These findings highlighted Malaysia's low readiness for solar power and shed some light on what needs to be done to be better prepared for solar power.
\end{abstract}

Keywords: attitude toward renewable energy; energy-conserving behaviors; renewable energy; solar photovoltaic panel; solar power

\section{Introduction}

\subsection{More Electricity Supply Is Needed in Malaysia}

Malaysia is a tropical country that includes Peninsular Malaysia, or West Malaysia, which has 11 states and East Malaysia which has two states-Sabah and Sarawak. The development of the economy has put Malaysia in high demand for electricity. According to Malaysia Energy Information Hub [1], the electricity demand per capita (kWh/person) has been increased from $626 \mathrm{kWh} /$ person in 1980 to $4549 \mathrm{kWh} /$ person in 2016. In 2015, 99.9\% of the households in Peninsular Malaysia enjoyed electricity, but only $95.1 \%$ of the households in Sabah and 94\% of the households in Sarawak had electricity supply in their household [2]. Acknowledging the increasing demand for electricity, the Malaysian government has included in the Eleventh Malaysia Plan for the years 2016 to 2020 [2] to aim for more sustainable, efficient, and reliable electricity supply. The planning was also in response to the global commitment of reducing greenhouse gas emissions by 2050. Given the COVID-19 situation, the government has postponed the announcement of the Twelfth Malaysia Plan (for the years 2021-2025) to 2021 [3]. Therefore, it is unclear whether renewable energy will be included in the subsequent plan.

\subsection{Steps to Actualizing the Plans}

To achieve the targets set by the Malaysian government and the global commitment, efforts are required from both the government and the public. These include, but are not limited to, developing renewable energy and improving the public's energy behaviors. 


\subsection{Developing Solar Power}

Due to its location near the equator, Malaysia is exposed to high temperature with daily solar radiation as high as $4500 \mathrm{kWh} / \mathrm{m}^{2}$ throughout the year [4]. Solar radiation can be converted into energy using solar photovoltaic (PV) cells, which usually come in the form of flat plates. The PV panels should be set at a fixed angle that faces south or designed with a tracking device to follow the sun [5]. Solar PV panels have been installed at the individual and commercial levels, for instance, in households or in large buildings. To supply sufficient power for a household, a few connected PV panels are sufficient. However, to supply power for a large building or large electric utility, hundreds of PV panels are required.

Despite the great potential for implementations of solar power, many countries are still battling several socioeconomic barriers to popularize the installation of solar PV panels. In Greece, the public has positive attitudes toward renewable energy and have good energy knowledge [6]. About $73 \%$ of the respondents in a Greek study [7] would invest in renewable energy, such as PV panels. However, the high installation fee is the main barrier from PV installation in Greece [6]. The situation is similar in Malaysia. The electricity prices in Malaysia are rather affordable compared to other countries [8], with the domestic rates ranging from RM0.218 to RM0.571/kWh (i.e., $€ 0.044$ to $€ 0.120 / \mathrm{kWh}$ ), the commercial rates from RM0.365 to RM0.509/kWh (i.e., $€ 0.074$ to $€ 0.100 / \mathrm{kWh}$ ), and industrial rates from RM0.337 to $\mathrm{RM} 0.441 / \mathrm{kWh}$ (i.e., $€ 0.068$ to $€ 0.089 / \mathrm{kWh}$ ) $[9,10]$. These rates are comparable with the solar energy price of RM0.218 to RM0.571/kWh (i.e., $€ 0.044$ to $€ 0.120 / \mathrm{kWh}$ ) sold from solar PV consumers to the national grid [11]. However, solar power has a high initial cost of installation. When the present study was conducted in 2018, Malaysians usually had to wait for 8 to 10 years to get a return of the investment in solar PV installations of a $4 \mathrm{~kW}-8 \mathrm{~kW}$ system [12], causing more potential Malaysian consumers to hesitate. Around the same period, the payback period was around 6 to 10 years in the United States [13], 6 to 8 years in Australia [14], and 12 years in Indonesia [15]. In a survey conducted in Malaysia in 2015 [16], 80\% of respondents showed interest in installing solar PV but were held back due to the cost and lack of information, and $82 \%$ of respondents would install if the cost was comparable with the cost of fossil fuel.

Another barrier is lack of awareness. Lack of the right information and awareness has been stopping the public from choosing renewable energy alternatives in various countries, such as Greece [6] and China [17]. A study conducted in Malaysia revealed the same issue [18]. The study showed that more than half of their respondents showed no concern for choosing renewable energy, and about $63 \%$ of the respondents were unaware of the availability of incentives for renewable energy. These statistics might seem discouraging. However, a similar survey [19] conducted two years later showed a slight increase in the public's interest in environmental issues and global warming, with $58 \%$ of respondents indicating interest. However, the respondents still hesitated to install solar power if the cost was higher than fossil fuels by only $10-20 \%$. Because of the barriers discussed above, the growth of solar energy in Malaysia has been slow. Only less than 2000 households installed solar PV systems in their homes in 2014 [20].

\subsection{Improving Energy Behaviors}

In conjunction with the global commitment of reducing greenhouse gas emissions by 2050, an online calculator tool [21] models how a wide number of factors affect climate change and global commitment. Based on the calculator tool, increasing reliance on renewable energy is only one of the approaches to reducing the emission of greenhouse gases. There are other approaches we have to take into consideration, for instance, the lifestyle factor. Lifestyle factors such as how far we travel, how big our buildings are, how many appliances there are in our homes, and our home temperature could contribute to the emission of greenhouse gases. These lifestyle factors can be referred to as energy behaviors. With more energy-conserving behaviors, we can contribute to decreasing the emissions of greenhouse gases. Therefore, it is important to cultivate energy-conserving behaviors among the public. 


\subsection{Research Aims and Significance}

There has been only a handful of studies investigating attitudes toward installing solar PV panels and energy behaviors in Malaysia. According to the study by Solangi and colleagues [19], which was conducted five years ago, there might be changes in the public's attitudes toward solar PV panels. Therefore, the present study aimed to examine the following research questions:

1. How well was the public aware of the option of installing solar PV panels?

2. How willing was the public to install solar PV panels?

3. Which factors were associated with the awareness of solar power, willingness to install solar PV panels, and energy-conserving behaviors? In particular, we explored several factors including psychological well-being (how happy and satisfied with life participants were) and knowledge about energy consumption.

\section{Materials and Methods}

\subsection{Participants and Design}

This study recruited 225 healthy volunteers. All participants who were above 18 were invited to participate (mean age was 30.17, the standard deviation of the age was 13.43), regardless of their gender and ethnicity. Most of the participants were recruited using the snowballing sampling method by approaching 15 Heriot-Watt University (HWU) Malaysia student helpers, who then approached their friends and family outside of HWU Malaysia. Therefore, almost half of the participants $(n=111,49.3 \%)$ were students. Other participants were full-time employees, such as doctors, lecturers, engineers, and accountants, business owners, and housewives. See Table A1 for the basic demographic characteristics of the sample.

There was a good balance of female $(48.4 \%)$ and male participants in our study. However, the percentage of female participants in our study was higher than the national average of $39 \%$ of the workforce being women [22]. More than half (52\%) of our participants received tertiary and postgraduate education, an average education level much higher than the national average where $55 \%$ of employed adults completed secondary school education [23]. There was a large proportion of participants with individual income less than RM1000 (€203). This is because many participants were students or housewives who did not have income. After removing the students, housewives, and those who did not indicate their occupation $(n=141)$, there was $61 \%$ of participants who earned at least RM3000 (€607) per month. A monthly income of RM3000 was comparable with the national mean personal monthly income of RM3087 ( $€ 624)$, albeit higher than the national median of RM2308 (€467) [24]. Most of the participants (63\%) never or seldom experienced interruption in electricity in the past year. This number was in line with the low electricity interruption rate $(0.1 \%)$ in firms in Malaysia [25]. Overall, our sample was overrepresented by women and individuals of higher education and high income as compared to the population.

This study employed a correlational research method by administering a series of questionnaires using the pen-and-pencil method. There were English and Malay versions of the questionnaires. Participants were given the English version of the questionnaire. But for those who had difficulty understanding English, they were given the Malay version.

\subsection{Procedure}

Since this study involved human participants, we submitted an ethics application to the ethics committee of the Department of Psychology at HWU. Once we obtained an ethics clearance, we started collecting data. We gave HWU Malaysia student helpers some questionnaires to distribute to their friends and family. All participants gave informed consent before completing the questionnaires. Each of them was assigned with a numeric code to protect their identities. 


\subsection{Measures}

A series of questionnaires were used to measure the study variables. The sequence presented to participants was as follows.

\subsubsection{The Satisfaction with Life (SWL) Scale}

This scale [26] measured how satisfied one is with her/his life. Some sample items included "If I could live my life over, I would change almost nothing" and "In most ways my life is close to my ideal." There were five items in this scale to be rated on a seven-point Likert scale from 1 (strongly disagree) to 7 (strongly agree). None of the items needed to be reverse-scored. In a study that tested the psychometric properties of the scale, Diener and colleagues reported high convergent validity of the scale as the scale was positively correlated with other scales measuring similar constructs. The scale is also suitable for individuals of various age groups [26]. In the present study, the scale had a high internal consistency with Cronbach's alpha value as high as 0.82 . We computed the SWL scores by averaging the items of the scale. Higher SWL scores indicated more satisfaction with life.

\subsubsection{The Oxford Happiness Questionnaire (OHQ—Short)}

OHQ-Short [27] is an eight-item scale that measures the level of happiness. Some sample items include "I feel that life is very rewarding" and "I do not have particularly happy memories of the past." Three of the eight items need to be reverse-scored. The scale is a shorter version of the original 29-item OHQ. Participants rated each item on a seven-point Likert scale from 1 (strongly disagree) to 7 (strongly agree). Both the OHQ and OHQ-Short had strong construct validity as they were positively correlated with scales that measured similar constructs (e.g., purpose in life and extraversion) and negatively correlated with scales measuring the opposite constructs (e.g., neuroticism and psychoticism) [27]. In the present study, the scale had a high internal consistency $(\alpha=0.61)$. Three items were reverse-scored before averaging the items of the OHQ to generate happiness scores. Higher happiness scores indicated greater happiness.

\subsubsection{The Energy Quiz}

This quiz was used to measure participants' knowledge of energy conservation and knowledge of renewable energy. It was adapted from Abrahamse, Steg, Vlek, and Rothengatter [28]. The original quiz from the paper by Abrahamse and colleagues had five multiple-choice questions. We adapted some items to make them more culturally appropriate. For instance, "Which appliance uses more energy, a washing machine or a video recorder?" was changed to "Which appliance uses more energy, a washing machine or a radio?" In addition, "What uses more energy, with a family of four, driving $16,000 \mathrm{~km}$ a year or flying to the West Coast of the US (from the Netherlands)?" was amended to "What uses more energy, with a family of four, driving $800 \mathrm{~km}$ from Perlis to Johor Bahru or flying from Perlis to Johor Bahru?" In addition to these questions, we added three multiple-choice questions that are related to solar PV panels. Specifically, one question asks whether they have seen a PV panel before; one question asks them about the function of PV panels; one question asks whether they have heard of large-scale PV farms. The scores of the energy quiz were computed by coding 1 for each correct answer and 0 for incorrect or no answer. The scores were then summed up to indicate knowledge in energy, where higher scores indicated greater knowledge in energy.

\subsubsection{Energy Attitude Scale}

This is a 14-item self-constructed questionnaire [29]. Three items measure attitudes toward renewable energy. The first item asking about awareness of the option of installing solar PV panels at home requires participants to indicate either "yes" or "no." The second item asks about the willingness ("yes" or "no") to install solar PV panels at home. The third item, which is to be rated on a Likert scale, asked participants to indicate the likelihood of installing solar PV panels at home even though it might 
cost between RM50,000 (€10,110) and RM70,000 (€14,153). Participants were to rate from 1 (not at all) to 6 (definitely). These three items were neither averaged nor summed as the items would be analyzed separately. The remaining 11 items measure attitudes toward a large-scale PV farm in Malaysia, which were not the scope of the present paper. Therefore, the data pertaining to these items were not reported in this paper.

\subsubsection{Energy Behavior Scale}

This is a 9-item self-constructed scale that measures energy-conserving behaviors, or in other words, the extent to which people conserve energy. Some of these items were adapted from Abrahamse et al. [28], such as items pertaining to the average temperature in houses and the number of light bulbs. Other sample questions include the number of times participants cook, the number of times participants use washing machine per week, and the number of hours participants watch television per day. All items have multiple choices for participants to choose one that best describes them. After reverse-scoring five items, we standardized the scores of each item and averaged the standardized scores to indicate energy behavior, with higher scores showing more positive energy behaviors.

\subsubsection{Demographic Questionnaire}

This is a seven-item scale to understand the demographic characteristics of the sample. The questions include the frequency of electricity interruption, age, gender, occupation, education level, individual income, and residential area.

\subsubsection{Malay Translation}

As the potential participants in this study might not have a good command of English, these questionnaires were translated into a Malay version. The participants who preferred Malay were given the Malay version of questionnaires, whereas those who preferred English were given the English version. To translate the questionnaires into Malay, the second author performed the Malay translation, and the third author back-translated the Malay version into an English version. The two translations were performed independently. The back-translated English version and the original English version were examined by the first author who found that the two versions were very close with each other, except for a few minor discrepancies. The translators discussed and resolved the discrepancies.

\section{Results}

\subsection{Data Preparation}

In preparing the data for analyses, we first imputed missing values. We replaced missing values with predicted values using the expectation-maximization technique with the Statistical Package for the Social Sciences (SPSS) for Windows (v.24). The SWL scale [26] had no missing values. However, three missing values were found in the OHQ-Short [27], and they were each replaced with a predicted value using the expectation-maximization technique. The missing values in the energy quiz were not replaced because they were meaningful (represented incorrect or no answer). Any missing value spotted in the energy behavior questionnaire was treated as "not applicable" or "answer not available." For instance, a missing value in the item regarding vehicles could mean the participant did not own a vehicle, and a missing value in the item related to the number of light bulbs in the house could mean the participant had no idea about the answer. Therefore, missing values were not replaced. After imputing missing values and reverse-scoring, we averaged or summed the scores for each questionnaire (see Table A2 for the means and standard deviations of the average and sum scores).

\subsection{Preliminary Analyses}

Correlational analyses were performed to examine the associations among the study variables. See Table A2 for the analysis findings. Participants who were more satisfied with life were in general 
happier, older, and having more income. Those who were happier also tended to have more income. Those who had a higher income were, as expected, older and had received higher education. Energy knowledge was not significantly associated with any variables, except for age, where people who had more energy knowledge tended to be younger. The majority of the participants $(n=217)$ completed the English version of the questionnaires, and the rest $(n=8)$ completed the Malay version of the questionnaires. To examine if the language version was associated with participants' responses, we performed a set of preliminary analyses. The results showed that those who completed the Malay version reported having lower levels of satisfaction, $t(223)=2.19, p=0.030$, happiness, $t(223)=2.18$, $p=0.030$, knowledge in energy, $t(223)=3.68, p<0.001$, and education level, $t(218)=3.16, p=0.002$. See Table A3 for the means and standard deviations of the variables by language versions. Subsequent analyses were performed with the language version controlled as a covariate.

\subsection{Main Analyses}

\subsubsection{Research Questions 1 and 2}

To answer the first two research questions, we performed some analyses to show the descriptive statistics. In general, there was a large proportion of participants $(n=203,90 \%)$ who could correctly identify the function of PV panels. When asked about whether they were aware of the option of individual installation of solar power, most of the participants $(n=166,74 \%)$ indicated that they were aware, and the rest $(n=59,26 \%)$ indicated that they were unaware. After explaining that solar power helps to reduce the emission of carbon dioxide, most of the participants $(n=189,84 \%)$ indicated that they would like to be a consumer of solar power. Only $36(16 \%)$ participants indicated unwillingness to be a consumer of solar power. However, once the participants were informed of the cost incurred for solar PV installation at home (between RM50,000 (€10,110) and RM70,000 $(€ 14,153)$ ), the participants rated a low level of willingness to install. On a 6-point Likert scale from 1 (not at all) to 6 (definitely) with a mid-point at 3.5, the average responses of participants were 3.04 , showing a tendency of unwillingness.

\subsubsection{Research Question 3}

In answering the third research question, we performed a series of Analyses of Covariance (ANCOVAs) to examine how people who had or did not have the awareness of installing solar panels at home differed in their psychological well-being, energy behaviors, and knowledge. Several significant and marginally significant findings were obtained in these analyses. Individuals who were aware of the option of installing solar panels at home had more energy knowledge than those who were not aware, $F(1,222)=32.04, p<0.001, \eta_{\mathrm{p}}^{2}=0.126$, and were more willing to install solar panels at home despite the high cost, $F(1,218)=6.27, p=0.013, \eta_{\mathrm{p}}{ }^{2}=0.028$. See Table A4 for the means and standard deviations of each group. These two groups of participants, however, did not differ in satisfaction with life, $F(1,222)=0.06, p=0.810, \eta_{\mathrm{p}}^{2}<0.001$, happiness, $F(1,222)=0.06, p=0.804, \eta_{\mathrm{p}}{ }^{2}<0.001$, and energy behavior, $F(1,222)=0.43, p=0.514, \eta_{p}^{2}=0.002$. We also performed another series of ANCOVAs to see how people who were willing or not willing to install solar PV panels differed in the dependent variables. Language version was controlled in these analyses as the covariate. Table A5 shows the means and standard deviations of individuals who were willing to install solar panels and those who were not willing. The results showed that individuals who indicated a willingness to install solar panels reported being less satisfied with life than those who were unwilling to install, $F(1,222)$ $=7.64, p=0.006, \eta_{\mathrm{p}}{ }^{2}=0.033$. Those who were willing to install solar panels also had more energy knowledge, $F(1,222)=5.74, p=0.017, \eta_{\mathrm{p}}^{2}=0.025$, and indicated a greater level of willingness to install solar panels at home despite the high cost, $F(1,218)=15.95, p<0.001, \eta_{\mathrm{p}}{ }^{2}=0.068$. However, these two groups did not differ in happiness, $F(1,222)=0.90, p=0.344, \eta_{\mathrm{p}}{ }^{2}=0.004$, and energy behavior, $F(1,222)=0.01, p=0.913, \eta_{\mathrm{p}}^{2}<0.001$. 
In general, the ANCOVA results showed that energy behaviors were not affected by the awareness of the option of installing solar PV panels and willingness to install solar PV panels. Energy behaviors also were not associated with energy knowledge, satisfaction with life, happiness, age, education level, and income (see Table A2 for the correlation coefficients).

\section{Discussion}

\subsection{Key Findings}

\subsubsection{Research Questions 1 and 2}

In general, most of our participants (90\%) had knowledge about PV panels as they could correctly identify the function of PV panels. The number of participants who were aware of the option of installing solar power at home was high, with almost three quarters $(74 \%)$ of the participants indicating awareness. There were even more participants ( $84 \%$ ) indicating a willingness to purchase solar power for their homes to help to reduce the emission of carbon dioxide. However, participants' willingness to support solar power was taken aback when they were informed of the cost incurred for installation at home. On a Likert-scale from 1 to 6, the mean was only 3.04, lower than the mid-point.

\subsubsection{Research Question 3}

The participants who were aware of the option of installing solar power generally had more energy knowledge and more willingness to install solar panels at home despite the high cost than those who were not aware. The participants who were willing to install solar PV, as compared to those who were unwilling, demonstrated more energy knowledge and indicated a greater level of willingness to install solar panels at home despite the high cost. However, those who were willing to install tended to be less satisfied with life. Whether participants were aware of the option of installing solar power and whether participants were willing to install did not affect their energy behaviors.

\subsection{Implications of the Study}

Our study investigated the readiness of Malaysia to embrace solar energy. We paid attention to the public's attitudes toward individual installation of solar PV panels and the public's energy-conserving behaviors. The findings we obtained could shed some light on the public's attitudes and energy behaviors and the approaches that promote the usage of solar power in Malaysia.

\subsubsection{Attitudes about Individual Installations of Solar Panels}

In Malaysia, there are two barriers that contribute to the low installation rate of solar PV panels at the individual and commercial levels. First, there has been a lack of awareness. Previous studies showed that Malaysians were in general not open-minded about renewable energy. The respondents in our study appeared to be somehow more supportive of renewable energy, as compared to the surveys conducted three to seven years ago $[16,18,19]$. About $70 \%$ of our participants were aware of the option of installing solar PV; $84 \%$ of our participants indicated a willingness to install solar PV; $90 \%$ of our participants knew the function of solar panels.

The second barrier is the high installation cost. The cost of installing solar PV panels in residential houses with the smallest system of $4 \mathrm{kWp}$ could cost about RM40,000 ( $€ 8073$ ). The return on investment is at least eight years [12]. Due to this reason, the rate and willingness for individual installations have been low. In previous studies conducted in Malaysia [16,18], the public did not appear to be supportive of solar PV installations due to the high cost. In our study, although more than $80 \%$ of participants indicated a willingness to install solar PV, they were taken aback after realizing the cost involved. After being told about the cost of installing solar panels (between RM50,000 and RM70,000, or between $€ 10,110$ and $€ 14,153$ ), the likelihood to install was on average 3.04 on a six-point Likert scale from 1 (not at all) to 6 (definitely), which was considered gearing toward the "unlikely" end. 
These findings hinted that Malaysians are increasingly aware of environmental issues and renewable energy options. However, the high installation cost is the main push factor. Such a situation could be found in other countries. In Indonesia, the people were not enthusiastic about the government's Rooftop Photovoltaic Solar Systems policy, with only 23\% of the respondents indicating interest and $71 \%$ waiting for other options [30]. The respondents expressed concerns over the high installation fee, low return on investment of eight to ten years, and lack of awareness of the policy [30]. In Greece, the public was supportive of renewable energy but was taken aback by the high installation fee and lack of accurate information [6]. In China, lack of awareness, financial difficulties, and low profitability are the main barriers [31].

To further boost the installation rate of solar PV in Malaysia, increasing awareness and setting policies and strategies directly targeting the reduction of the cost of installation are crucial. Countries that have higher solar PV panel installation rates, such as Italy and Germany, generally have attractive $\mathrm{kWh}$ prices, lower bank loan rates, and tax reductions [6]. The feed-in tariffs in Germany range from $€ 0.107$ to $€ 0.123$ per $\mathrm{kWh}$ [32] and those in Italy from $€ 0.112$ to $€ 0.182 \mathrm{kWh}$ [33], as compared to RM0.218 to $\mathrm{RM} 0.571 / \mathrm{kWh}$ (i.e., $€ 0.044$ to $€ 0.120 / \mathrm{kWh}$ ) in Malaysia [11]. Germany bases its renewable energy success on an eco-friendly culture, improved technology on energy storage, allowing its citizens to sell energy to the national grid with attractive $\mathrm{kWh}$ prices $[34,35]$. The Italian government has recently announced a $110 \%$ support for solar PV installations of certain renovation projects, or in other words, there will be zero PV installation fees for such projects [36].

There have been efforts from the Malaysian government for such purposes, despite some offers being less attractive compared to those found in Italy and Germany. The Malaysian government has provided incentives to PV panels installation, such as tax allowance for solar energy consumers until the end of 2020 [37]. Solar energy consumers who purchase green technology assets, such as solar air-conditioning equipment, could get tax allowance, and companies participating in new green technology activities, such as generating energy using solar power, could get income tax exemptions [38]. The government has also initiated the net energy metering (NEM) programme [39] that allows users to install solar PV panels to generate energy for consumption. Users may sell the excess of the energy produced to an electric utility company with the feed-in tariffs being the same as the self-consumption tariffs (between $€ 0.044$ and $€ 0.120 / \mathrm{kWh}$ ) [11], which are lower than the feed-in tariff of RM1.04/kWh (i.e., $€ 0.210 / \mathrm{kWh}$ ) in 2014 [40]. Nevertheless, the NEM scheme has provided a better offer compared to the previous scheme where the feed-in tariffs were lower than self-consumption tariffs [41]. The NEM scheme also turns the upfront cost into a monthly leasing fee, allowing users to pay zero upfront costs [39]. Such an incentive pales in comparison with the zero installation fee in Italy [36]. As of 2019, the scheme has approved $108 \mathrm{MW}$ of installation from users [42], way behind its target of $500 \mathrm{MW}$ by the end of 2020 [43].

Private solar power-related companies in Malaysia, such as Solarvest, have been active in organizing campaigns, nationwide roadshows, and talks to share the benefits of solar power with the public [44]. These efforts sometimes have teamed up with banks to provide financing solutions to reduce to initial investment cost of installing PV panels [44]. Such events could attract about 100 attendees in each event [44]. However, we need further data to investigate how many participants signed up for the programs, how helpful these initiatives were in promoting awareness, and the demographic characteristics of the attendees.

Since the individual installation of solar PV panels is not gaining its popularity due to the high cost, another alternative for consuming solar power is large-scale implementations of solar power. This approach requires large-scale solar (LSS) plants that generate solar power and feed the energy to the national grid, which then combines solar energy with energy from other sources (e.g., biogas, biomass, and hydropower). This method does not require individual installation and may overcome the issues pertaining to high cost. Tenaga Nasional Berhad (TNB) has launched a project to purchase solar power via LSS plants in 2017. TNB is the Malaysian multinational electricity company and is the only electric utility company in Peninsular Malaysia. It is a government-linked company and is owned 
by the government indirectly. TNB has signed a 21-year agreement to purchase solar power from a 98-hectare solar farm located in Banting, Selangor, under Malaysia's first LSS scheme [45]. Two other LSS projects launched by the Malaysian government and the fourth 1GW LSS project currently opened for bidding will be feeding solar energy to the national grid [46]. In a survey conducted in Malaysia in 2020, the public showed supportiveness of the implementation of LSS plants and the development of renewable energy in the country [29]. Such findings are encouraging and indicate LSS implementation as a feasible alternative to the individual installation of solar PV.

One thing to keep in mind is that the development of solar energy should remain one of the essential parts of the economic development in Malaysia. Countries that set clear national goals for renewable energy development generally have higher solar PV penetration rates (e.g., [34]). With higher per capita gross domestic product, solar panels will be more affordable, and people will be more willing to pay for solar energy [47].

\subsubsection{Energy-Conserving Behaviors}

It is expected that having awareness of individual installations and/or willingness to install solar PV panels would be associated with energy-conserving behaviors. Our findings showed that awareness and willingness did not affect participants' energy-related behaviors.

In general, the energy behaviors of our participants were rather disappointing with an average of 2.50 (raw scores), where the highest possible raw score is 9 which indicates the best positive energy behaviors. With the current level of positive energy behaviors, the chances of Malaysia reaching the international standard of greenhouse gas emissions could be slim. In addition to developing the technology of renewable energy, it is crucial to change Malaysians' energy behaviors. We strongly recommend more research effort to investigate the factors that would promote energy behaviors among the Malaysians.

\subsection{Limitations and Suggestions for Future Studies}

As one of a handful of studies that examined the public's responses to renewable energy in Malaysia, the study provided several important theoretical and practical implications. However, the findings of the present study should be interpreted with caution due to the following limitations.

The sample in this study might not be representative of the people in Malaysia. The participants recruited from this study were mainly well versed in English as most of them completed the English version of the questionnaire. They were also highly educated and had a high income. Although there was a small proportion of less educated and low-income participants in our study, they might not be well represented in the present study. Therefore, some of the findings of the present study might not be representative. For instance, the high percentage of awareness of individual installation of solar PV and the supportiveness for renewable energy might be overrepresented by the high income, high education group in the sample. Furthermore, most of our participants came from West Malaysia. The East Malaysians' opinions and attitudes were not well represented in this study.

One of the items asked participants their likelihood of installing solar PV panels given the cost of between RM50,000 and RM70,000. However, this study did not provide further information regarding the long-term savings. Such unbiased information is needed for participants to make an informed decision. This study also did not measure other potential barriers to installation, such as access to installers and information about the incentives from the government.

Some analyses in this study divided participants into groups, such as participants who were aware versus unaware of solar PV panel installation. These categorizations were based on self-perception responses, which might be different from objective measures. For a different categorization, future studies may base the categorization on objective measures, such as measures of knowledge about solar PV panels.

Our participants, in general, showed a lack of energy-conserving behaviors. It is intriguing that even having energy knowledge did not affect their energy behaviors. Since energy behaviors are 
important in conserving energy and maintaining a sustainable environment, we would like to urge more research to figure out significant factors that may help to improve energy behaviors among Malaysians.

\section{Conclusions}

As one of the limited number of studies that investigated Malaysians' attitude toward solar energy and Malaysians' energy behaviors, our study provided important findings and implications for social issue campaigns and policymakers. We examined two psychosocial conditions necessary for meeting the higher demand for electricity, namely the awareness of renewable energy and energy-conserving behaviors. We found that while the public met the first condition, with most of them having knowledge about renewable energy, they did not satisfy the second condition with the respondents showing a rather disappointing level of energy-conserving behaviors. Furthermore, we noticed that despite having the willingness to install PV panels, the respondents were hesitant in turning such willingness into action due to the cost incurred. Our findings highlighted the efforts needed to prepare Malaysia for the development of renewable energy.

Author Contributions: Conceptualization, Y.I.G.; Methodology, A.N.T.; Investigation; A.N.T., Y.I.G., and T.C.Y.; Formal analysis A.N.T.; Writing-original draft preparation, A.N.T.; Writing-Review and editing, Y.I.G. and T.C.Y.; Project administration: Y.I.G. and A.N.T.; Funding acquisition, Y.I.G. All authors have read and agreed to the published version of the manuscript.

Funding: This research was funded by Fledge Funding, Energy Academy, Heriot-Watt University, United Kingdom. Conflicts of Interest: The authors declare no conflict of interest.

\section{Appendix A}

Table A1. The demographic characteristics of the sample.

\begin{tabular}{cccc}
\hline Variable & Categories & Number of Participants & Percentage \\
\hline \multirow{3}{*}{ Gender } & Female & 109 & 48.4 \\
& Male & 113 & 50.2 \\
& Did not indicate & 3 & 1.3 \\
& Primary school & 4 & 1.8 \\
& Secondary school & 51 & 22.7 \\
Highest education & Diploma & 48 & 21.3 \\
& Bachelor & 91 & 40.4 \\
& Master & 20 & 8.9 \\
& Doctorate & 6 & 2.7 \\
& Did not indicate & 5 & 2.2 \\
& Less than RM1000 & 102 & 45.3 \\
& RM1000-RM2000 & 14 & 6.2 \\
& RM2000-RM3000 & 20 & 8.9 \\
RM3000-RM4000 & 21 & 9.3 \\
& RM4000-RM5000 & 12 & 5.3 \\
& RM5000-RM6000 & 12 & 5.3 \\
& RM6000 and above & 28 & 12.4 \\
& Did not indicate & 16 & 7.1 \\
& 0-Never & 39 & 17.3 \\
& 1 & 102 & 45.3 \\
& 2 & 46 & 20.4 \\
Fuestionnaire version & 3-Always & 21 & 9.3 \\
& Did not indicate & 17 & 7.6 \\
& English & 217 & 96.4 \\
& Malay & 8 & 3.6 \\
\hline
\end{tabular}


Table A2. The correlation coefficients among variables.

\begin{tabular}{cccccccc}
\hline & $\mathbf{1}$ & $\mathbf{2}$ & $\mathbf{3}$ & $\mathbf{4}$ & $\mathbf{5}$ & $\mathbf{6}$ & $\mathbf{7}$ \\
\hline 1. SWL & 1.00 & & & & & & \\
2. Happiness & $0.58^{* *}$ & 1.00 & & & & & \\
3. Energy behavior & -0.06 & -0.12 & 1.00 & & & & \\
4. Energy & -0.04 & 0.09 & 0.07 & 1.00 & & & \\
knowledge & $0.17^{*}$ & $0.17^{*}$ & -0.01 & $-0.24^{* *}$ & 1.00 & & \\
$\quad$ 5. Age & 0.11 & 0.13 & 0.09 & 0.05 & -0.03 & 1.00 & \\
6. Education level & $0.21^{* *}$ & $0.21^{* *}$ & 0.00 & -0.11 & $0.63 * *$ & $0.33 * *$ & 1.00 \\
7. Income & 4.86 & 4.69 & 0.00 & 5.73 & 30.17 & 4.41 & 2.88 \\
$\quad$ Means & 1.08 & 0.71 & 3.34 & 1.59 & 13.43 & 1.08 & 2.24 \\
Standard deviations &
\end{tabular}

Note. SWL $=$ satisfaction with life. ${ }^{*} p<0.05,{ }^{* *} p<0.01$.

Table A3. The means and standard deviations of the variables by language version.

\begin{tabular}{cccc}
\hline & & English & Malay \\
\hline SWL & $n$ & 217 & 8 \\
& $M$ & $4.89_{\mathrm{a}}$ & $4.05_{\mathrm{b}}$ \\
Happiness & $S D$ & 1.06 & 1.23 \\
& $n$ & 217 & 8 \\
Energy behavior & $M$ & $4.71_{\mathrm{a}}$ & $4.16_{\mathrm{b}}$ \\
& $S D$ & 0.71 & 0.56 \\
Energy knowledge & $n$ & 217 & 8 \\
& $M$ & 0.04 & -1.12 \\
Education level & $S D$ & 3.37 & 2.63 \\
& $n$ & 217 & 8 \\
Income & $M$ & $5.80_{\mathrm{a}}$ & $3.75_{\mathrm{b}}$ \\
& $S D$ & 1.56 & 1.16 \\
& $n$ & 212 & 8 \\
& $M$ & $4.45_{\mathrm{a}}$ & $3.25_{\mathrm{b}}$ \\
& $S D$ & 1.07 & 0.71 \\
& $n$ & 201 & 8 \\
& $M$ & 2.89 & 2.75 \\
& $S D$ & 2.28 & 0.89
\end{tabular}

Note. SWL = satisfaction with life, $n=$ number of participants, $M=$ mean, $S D=$ standard deviation. The means in the same row with different subscripts differed significantly from each other.

Table A4. The descriptive statistics of individuals with or without awareness of the option of installing solar panels at home.

\begin{tabular}{cccccc}
\hline \multirow{2}{*}{ Topics } & Variables & \multicolumn{2}{c}{ Yes } & \multicolumn{2}{c}{ No } \\
\cline { 3 - 6 } & & Mean & SD & Mean & SD \\
\hline \multirow{2}{*}{ Psychological well-being } & satisfaction with life & 4.87 & 1.09 & 4.83 & 1.05 \\
Energy behaviors & happiness & 4.71 & 0.76 & 4.64 & 0.57 \\
Energy knowledge & & 0.11 & 3.38 & -0.32 & 3.26 \\
Demographic variables & age & 6.10 & 1.40 & 4.69 & 1.65 \\
& education level & 29.92 & 13.93 & 30.89 & 11.95 \\
income & 2.40 & 1.09 & 4.42 & 1.05 \\
Energy attitudes & willingness to & & 2.32 & 3.04 & 2.02 \\
& purchase PV panels & 3.21 & 1.51 & 2.54 & 1.44 \\
& for home & & & & \\
\hline
\end{tabular}


Table A5. The descriptive statistics of individuals who were willing and those who were unwilling to install solar panels.

\begin{tabular}{cccccc}
\hline \multirow{2}{*}{ Topics } & Variables & \multicolumn{2}{c}{ Yes } & \multicolumn{2}{c}{ No } \\
\cline { 3 - 5 } & & Mean & SD & Mean & SD \\
\hline \multirow{2}{*}{ Psychological well-being } & satisfaction with life & 4.80 & 1.04 & 5.21 & 1.22 \\
Energy behaviors & happiness & 4.72 & 0.71 & 4.53 & 0.72 \\
Energy knowledge & & 0.01 & 3.39 & -0.07 & 3.13 \\
& & 5.87 & 1.55 & 4.97 & 1.61 \\
Demographic variables & age & 30.21 & 13.90 & 29.97 & 10.84 \\
& education level & 4.43 & 1.09 & 4.28 & 1.00 \\
& income & 2.84 & 2.28 & 3.09 & 2.07 \\
Energy attitudes & willingness to & & & & \\
& purchase PV panels & 3.22 & 1.48 & 2.03 & 1.31 \\
& for home & & & & \\
\hline
\end{tabular}

Note. $S D=$ standard deviation, $\mathrm{PV}=$ photovoltaic.

\section{References}

1. Malaysia Energy Information Hub. Economic Data Analysis: Energy Indicator-Energy Intensity per Capita. 2018. Available online: http://meih.st.gov.my/statistics?p_auth=OvfhXSR2\&p_p_id=Eng_Statistic_WAR_ STOASPublicPortlet\&p_p_lifecycle=1\&p_p_state=maximized\&p_p_mode=view\&p_p_col_id=column$1 \&$ p_p_col_pos=1\&p_P_col_count=2\&_Eng_Statistic_WAR_STOASPublicPortlet_execution=e1s1\&_Eng Stat (accessed on 1 May 2020).

2. Economic Planning Unit. The Eleventh Malaysia Plan (11 MP) 2016-2020. 2015. Available online: https://www.talentcorp.com.my/clients/TalentCorp_2016_7A6571AE-D9D0-4175-B35D-99EC514F2D24/ contentms/img/publication/RMKe-11Book.pdf (accessed on 1 May 2020).

3. The Malaysian Reserve. Govt Plans to Table 12th Malaysia Plan early 2021. 2020. Available online: https://themalaysianreserve.com/2020/07/06/govt-plans-to-table-12th-malaysia-plan-early-2021/ (accessed on 23 July 2020).

4. Shafie, S.M.; Mahlia, T.M.I.; Masjuki, H.H.; Andriyana, A. Current energy usage and sustainable energy in Malaysia: A review. Renew. Sustain. Energy Rev. 2011, 15, 4370-4377. [CrossRef]

5. Sustainable Energy Development Authority Malaysia. National Renewable Energy Policy and Action Plan. 2008. Available online: http://www.seda.gov.my/?omaneg= $00010100000001010101000100001000000000000000000000 \& s=31$ (accessed on 1 May 2020).

6. Ntanos, S.; Kyriakopoulos, G.; Chalikias, M.; Arabatzis, G. Public Perceptions and Willingness to Pay for Renewable Energy: A Case Study from Greece. Sustainability 2018, 10, 687. [CrossRef]

7. Skordoulis, M.; Ntanos, S.; Arabatzis, G. Socioeconomic evaluation of green energy investments. Int. J. Energy Sect. Manag. 2020. [CrossRef]

8. New Straits Time. Malaysia has Fourth Lowest Domestic Electricity Tariff in the World. 2018. Available online: https://www.nst.com.my/news/nation/2018/02/331983/malaysia-has-fourth-lowestdomestic-electricity-tariff-world (accessed on 1 May 2020).

9. Tenaga Nasional Berhad. Residential: Pricing and Tariffs. 2020. Available online: https://www.tnb.com.my/ residential/pricing-tariffs (accessed on 20 July 2020).

10. Tenaga Nasional Berhad. Commercial and Industrial: Pricing and Tariffs. 2020. Available online: https: //www.tnb.com.my/commercial-industrial/pricing-tariffs1/ (accessed on 20 July 2020).

11. EdgeProp. Go Solar and Save on Your Electricity Bill. 2019. Available online: https://www.edgeprop.my/ content/1541671/go-solar-and-save-your-electricity-bill (accessed on 20 July 2020).

12. The Edge Markets. Going Green: Better Returns Solar Investments Expected. 2018. Available online: https://www.theedgemarkets.com/article/going-green-better-returns-solar-investments-expected (accessed on 23 July 2020).

13. PV Magazine. Are Solar Panels Worth It? 2017. Available online: https://pv-magazine-usa.com/2017/10/20/ are-solar-panels-worth-it/ (accessed on 23 July 2020). 
14. Imteaz, M.A.; Ahsan, A. Solar panels: Real efficiencies, potential productions and payback periods for major Australian cities. Sustain. Energy Technol. Assess. 2018, 25, 119-125. [CrossRef]

15. PV Magazine. The Weekend Read: PV Could Help Clear Indonesia Air. 2019. Available online: https: //www.pv-magazine.com/2019/11/02/the-weekend-read-pv-could-help-clear-indonesias-air/ (accessed on 23 July 2020).

16. Solangi, K.H.; Saidur, R.; Luhur, M.R.; Aman, M.M.; Badarudin, A.; Kazi, S.N.; Lwin, T.N.W.; Rahim, N.A.; Islam, M.R. Social acceptance of solar energy in Malaysia: Users' perspective. Clean Technol. Environ. Policy 2015, 17, 1975-1986. [CrossRef]

17. Yuan, X.; Zuo, J.; Ma, C. Social acceptance of solar energy technologies in China-End users' perspective. Energy Policy 2011, 39, 1031-1036. [CrossRef]

18. Muhammad-Sukki, F.; Ramirez-Iniguez, R.; Abu-Bakar, S.H.; Scott, G.M.; Brian, G.S. An evaluation of the installation of solar photovoltaic in residential houses in Malaysia: Past, present and future. Energy Policy 2011, 39, 7975-7987. [CrossRef]

19. Solangi, K.H.; Badarudin, A.; Kazi, S.N.; Lwin, T.N.W.; Aman, M.M. Public acceptance of solar energy: The case of Peninsular Malaysia. TENCONSpring 2013 Conf. Proc. 2013, 540-543. [CrossRef]

20. The Star Online. Energised by the Sun. 2014. Available online: https://www.thestar.com.my/news/ environment/2014/02/24/energised-by-the-sun/ (accessed on 1 July 2020).

21. The Global Calculator. The Global Calculator v.23. 2015. Available online: http://tool.globalcalculator. org/globcalc.html?levers=22rfoe2e13be1111c2c2c1n31hfjd2ef222hp233f211111fn2211111111/technology/en (accessed on 1 May 2020).

22. TalentCorp. Key Figures: A Quick Glance at Malaysia. 2018. Available online: https://www.talentcorp.com. my/key-figures/key-figures (accessed on 1 May 2020).

23. Statistica. Number of Employed Persons in Malaysia in 2018, by Education Level. 2020. Available online: https://www.statista.com/statistics/794752/employed-persons-by-education-level-malaysia/ \#statisticContainer (accessed on 20 July 2020).

24. Malaysia, Department of Statistics. Salaries and Wages Survey Report, Malaysia, 2018.2019. Available online: https://www.dosm.gov.my/v1/index.php?r=column/cthemeByCat\&cat=157\&bul_id= cTNsWU5yd291RmNiQnQvdklFNGFEZz09\&menu_id=U3VPMldoYUxzVzFaYmNkWXZteGduZz09 (accessed on 20 July 2020).

25. The World Bank Group. Power Outages in Firms in a Typical Month (Number). 2020. Available online: https://data.worldbank.org/indicator/IC.ELC.OUTG (accessed on 20 July 2020).

26. Diener, E.; Emmons, R.A.; Larsen, R.J.; Griffin, S. The Satisfaction with Life Scale. J. Personal. Assess. 1985, 49, 71-75. [CrossRef] [PubMed]

27. Hills, P.; Argyle, M. The Oxford Happiness Questionnaire: A compact scale for the measurement of psychological well-being. Personal. Individ. Differ. 2002, 33, 1073-1082. [CrossRef]

28. Abrahamse, W.; Steg, L.; Vlek, C.; Rothengatter, T. The effect of tailored information, goal setting, and tailored feedback on household energy use, energy-related behaviours, and behavioural antecedents. J. Environ. Psychol. 2007, 27, 265-276. [CrossRef]

29. Teoh, A.N.; Go, Y.I.; Yap, T.C. Psychosocial implications of large-scale implementations of solar power in Malaysia. Technologies 2020, 8, 26. [CrossRef]

30. Setyawati, D. Analysis of perceptions towards the rooftop photovoltaic solar system policy in Indonesia. Energy Policy 2020, 144, 111569. [CrossRef]

31. Cai, X.; Xie, M.; Zhang, H.; Xu, Z.; Cheng, F. The business model of distributed solar photovoltaic power of China: The business model canvas perspective. Sustainability 2019, 11, 4322. [CrossRef]

32. PV Magazine. Feed-in Tariffs in Europe-Germany. 2014. Available online: https://www.pv-magazine.com/ features/archive/solar-incentives-and-fits/feed-in-tariffs-in-europe/\#germany (accessed on 23 July 2020).

33. PV Magazine. Feed-in Tariffs in Europe-Italy. 2014. Available online: https://www.pv-magazine.com/ features/archive/solar-incentives-and-fits/feed-in-tariffs-in-europe/\#italy (accessed on 23 July 2020).

34. National Geographic. Germany Could be a Model for How We'll Get Power in the Future. 2015. Available online: https://www.nationalgeographic.com/magazine/2015/11/germany-renewable-energy-revolution/ (accessed on 23 July 2020). 
35. Clean Energy Wire. Solar Power in Germany-Output, Business and Perspectives. 2020. Available online: https://www.cleanenergywire.org/factsheets/solar-power-germany-output-business-perspectives (accessed on 23 July 2020).

36. PV Magazine. Italian Homeowners Can Now Install PV Systems for Free. 2020. Available online: https: //www.pv-magazine.com/2020/05/22/italian-homeowners-can-now-install-pv-systems-for-free/ (accessed on 23 July 2020).

37. Malaysian Investment Development Authority. Tax Incentives for Green Industry. 2018. Available online: http://www.mida.gov.my/home/tax-incentives-for-green-industry/posts/ (accessed on 1 July 2020).

38. MyHIJAU. Green Incentives. 2017. Available online: https://www.myhijau.my/green-incentives/ (accessed on 1 July 2020).

39. Sustainable Energy Development Authority. Net Energy Metering. 2019. Available online: https://www. seda.gov.my/2019/02/net-energy-metering-nem/ (accessed on 20 July 2020).

40. The Star. Understanding FiT. 2014. Available online: https://www.thestar.com.my/news/environment/2014/ 02/24/understanding-fit/ (accessed on 20 July 2020).

41. The Edge Markets. Beginning 2019, No Price Difference Between Solar Generation and Consumption Tariff. 2018. Available online: https://www.theedgemarkets.com/article/beginning-2019-no-price-differencebetween-solar-generation-and-consumption-tariff (accessed on 20 July 2020).

42. Sustainable Energy Development Authority. SEDA Malaysia: A Report Card 2019 Strengthens the Growth of Renewable Energy and Its Industry in Malaysia. 2020. Available online: http://www.seda.gov.my/2020/01/seda-malaysia-a-report-card-2019-strengthens-the-growth-ofrenewable-energy-and-its-industry-in-malaysia/ (accessed on 20 July 2020).

43. Sustainable Energy Development Authority. SMEs Urged to Participate in NEM Programme-Yeo. 2019. Available online: https://www.seda.gov.my/2019/05/smes-urged-to-participate-in-nem-programme-yeo/ (accessed on 20 July 2020).

44. Solarvest. Solarvest and UOB Teaming up to Promote Solar Energy. 2019. Available online: https: //solarvest.my/2019/10/11/solarvest-uob-teaming-up-to-promote-solar-energy/ (accessed on 20 July 2020).

45. The Star Online. TNB Gets RM339mil Financing for Kuala Langat Solar Project. 2017. Available online: https://www.thestar.com.my/business/business-news/2017/08/16/tnb-gets-rm339mil-financing-forkuala-langat-solar-project/ (accessed on 1 July 2020).

46. New Straits Time. Malaysia Opens RM4 Bil Bid for 1GW of Solar Plants. 2020. Available online: https://www.nst.com.my/business/2020/06/598704/malaysia-opens-rm4-bil-bid-1gw-solar-plants (accessed on 20 July 2020).

47. Jin, J.; Wan, X.; Lin, Y.; Kuang, F.; Ning, J. Public willingness to pay for the research and development of solar energy in Beijing, China. Energy Policy 2019, 134, 110962. [CrossRef]

(C) 2020 by the authors. Licensee MDPI, Basel, Switzerland. This article is an open access article distributed under the terms and conditions of the Creative Commons Attribution (CC BY) license (http://creativecommons.org/licenses/by/4.0/). 